\title{
UMA ANÁLISE DO PROCESSO DE DESENVOLVIMENTO HUMANO A PARTIR DE EXPERIÊNCIAS NO CSF
}

\author{
P. B. CICHOSKI, M. RUBIN-OLIVEIRA, E. S. TEIXEIRA* \\ Programa de Pós-Graduação em Desenvolvimento Regional, Universidade Tecnológica Federal do Paraná \\ paulasbottega@hotmail.com \\ Submetido 03/08/2017 - Aceito 22/11/2018 \\ DOI: $10.15628 /$ holos.2018.6180
}

\section{RESUMO}

O artigo relata investigação que teve por objetivo analisar como experiências de internacionalização desenvolvidas no âmbito do Programa Ciência sem Fronteiras (CSF) implicam o desenvolvimento humano de estudantes de graduação do Campus Francisco Beltrão, da Universidade Tecnológica Federal do Paraná (UTFPR), localizado na região sudoeste do Paraná. Participaram do estudo 13 (81,25\%) estudantes, 7 do sexo masculino e 6 do sexo feminino, do total de 16 que participaram do CSF no Câmpus. O grupo era formado por graduandos Engenharia Ambiental, Engenharia de Alimentos, Engenharia Química, Licenciatura em Informática e Tecnologia em Alimentos. Foram realizadas entrevistas semiestruturadas e mediante princípios de análise do conteúdo foi possível identificar as categorias Cultura e Autonomia. Língua, Visão de Mundo, Preconceito, Hábitos Alimentares, Rotina de Estudos, foram os elementos que emergiram nas entrevistas e que sustentam a categoria Cultura. Os elementos Independência, Maturidade, Responsabilidade, Autoconhecimento, Coragem e Disciplina, por sua vez, sustentam o que denominamos como a categoria Autonomia neste estudo. A partir do processo de análise, pode-se inferir que a experiência internacional, proporcionada pelo Programa Ciência Sem Fronteiras, trouxe a cada um dos estudantes um processo de mudança, ou seja, ela proporcionou a eles implicações em seus desenvolvimentos humanos.

PALAVRAS-CHAVE: Desenvolvimento Humano, Internacionalização, Educação Superior, Estudantes.

\section{AN ANALYSIS OF THE HUMAN DEVELOPMENT PROCESS FROM CSF EXPERIENCES}

\begin{abstract}
This paper report an investigation aimed at analyzing how internationalization experiences developed under the Programa Ciência Sem Fronteira (CSF) imply the human development of undergraduate students from the Francisco Beltrão Campus, from the Universidade Tecnológica Federal do Paraná (UTFPR ), located in the southwest region of Paraná. Thirteen (81.25\%) participated in the study, 7 male and 6 female, out of a total of 16 who participated in the CsF on the Campus. The group was graduated in Environmental Engineering, Food Engineering, Chemical Engineering, Degree in Computer Science and Food Technology. Semistructured interviews were carried out and through content
\end{abstract}

analysis principles it was possible to identify the categories Culture and Autonomy. Language, World Vision, Prejudice, Eating Habits, Routine of Studies, were the elements that emerged in the interviews that support what we call the Culture category. The elements Independence, Maturity, Responsibility, Self-knowledge, Courage and Discipline, which, in turn, support what we call the Autonomy category in this study. From the analysis process, it can be inferred that the international experience, provided by the Science Without Borders Program, brought to each of the students a process of change, that is, it gave them implications in their human development.

KEYWORDS: Human Development, Internationalization, Higher Education, Students. 


\section{APRESENTAÇÃO}

O presente artigo é um dos resultados de um projeto de pesquisa intitulado Desafios da Internacionalização da Educação Superior Brasileira: universidades de classe mundial ${ }^{1}$, que tem como objetivo refletir sobre universidades de classe mundial, os movimentos e políticas públicas que buscam inserir as universidades brasileiras nesse contexto. Mais especificamente, relata-se aqui uma investigação que teve por objetivo analisar como experiências de internacionalização desenvolvidas no âmbito do Programa Ciência sem Fronteiras (CSF) implicam o desenvolvimento humano de estudantes de graduação do Campus Francisco Beltrão, da Universidade Tecnológica Federal do Paraná (UTFPR), localizado na região sudoeste do Paraná. Esse é o programa de maior impacto dentre os estudantes da instituição pesquisada.

A Internacionalização da Educação Superior é um conjunto de ações, políticas e programas que apontam para maiores interações, com distintas ênfases, entre as universidades e o cenário internacional de globalização. Para Knight (2010; 2012; 2014) e Morosini (1997; 2006) trata-se de um esforço da Educação Superior para atingir as exigências e desafios que se relacionam com a globalização da sociedade, da economia e do mercado de trabalho, em que há uma maior exigência das pessoas estarem mais interconectadas com as mudanças globais.

Nesse contexto é que inseriu-se o programa Ciência sem Fronteiras ${ }^{2}$, criado em 2011 a partir de ações conjuntas dos Ministérios da Ciência, Tecnologia e Inovação (MCTI) e do Ministério da Educação (MEC), por meio de suas instituições de fomento (CNPQ e CAPES) e Secretarias de Ensino Superior e de Ensino Tecnológico do MEC. O objetivo era promover a consolidação, a expansão e a internacionalização da ciência e tecnologia, da inovação e da competitividade brasileira através do intercâmbio e da mobilidade internacional (MEC, 2015).

A intenção do governo federal era fornecer 101 mil bolsas aos estudantes distribuídas entre as seguintes modalidades: Doutorado Sanduíche, Doutorado Pleno, Pós-Doutorado, Graduação Sanduíche, Desenvolvimento Tecnológico e Inovação no Exterior, Atração de Jovens Talentos e Pesquisador Visitante Especial. Do total de bolsas oferecidas, 64.000 estavam previstas para a Graduação Sanduíche, meta cuja intenção era ser cumprida até o ano de 2015 (MEC, 2015).

Durante a vigência do Programa estudantes foram enviados para uma diversidade de 23 países, cujos estudos foram realizados em um montante de mais de 100 universidades. As áreas eleitas como prioridades eram 18, entre elas as engenharias, tecnologias e saúde, não sendo contempladas as áreas de ciências humanas (CUNHA \& RESCHKE, 2016). O Programa trouxe para os estudantes de graduação das universidades brasileiras "a possibilidade de acesso ao conhecimento em âmbito internacional, de apresentação do potencial dos brasileiros nas interações acadêmicas, da troca de experiências culturais e do contato dos estudantes com alguns expoentes do meio científico mundial" (BIDO, 2016, p. 61).

\footnotetext{
${ }^{1}$ Chamada Universal - MCTI/CNPQ n ${ }^{\circ} .14 / 2014$.

${ }^{2} \mathrm{O}$ Programa Ciência sem Fronteiras (CsF) teve o último edital para graduação 2014.
} 
O objetivo da internacionalização não é propriamente internacionalizar currículos, tampouco incrementar a mobilidade acadêmica. Ao invés disso, "o objetivo é garantir que os estudantes estejam mais preparados para viver e trabalhar num mundo mais interconectado" (KNIGHT, 2012, p. 65). Com efeito, a convivência com novas culturas, com pessoas diferentes, costumes e tradições diferentes, novas formas de resolução de conflitos e problemas, situações nunca antes vivenciadas, que são vividas intensamente em um curto espaço de tempo e que podem proporcionar uma nova forma de interpretar o mundo, pode propiciar aos estudantes que participam desses programas diversos aprendizados que implicam mudanças significativas em processo pessoal de desenvolvimento.

Por desenvolvimento humano, na pesquisa aqui desenvolvida, compreende-se o conjunto de processos que ocorrem durante toda a vida da pessoa. É a partir das aprendizagens que o sujeito tem, através das interações que são estabelecidas com e em seu entorno, que o sujeito vai se modificando e se desenvolvendo (VIGOTSKI, 1995). Essas aprendizagens são influenciadas pelo contexto social e histórico ao qual ele pertence, numa relação de interação que acontece a partir do nascimento, até o fim da vida.

Por conseguinte, o homem se desenvolve de acordo com a sociedade em que ele está inserido, bem como do contexto histórico, político e econômico do qual ele faz parte. Por sua vez, esses contextos influenciam diretamente na forma como a educação e, de forma específica, como a universidade vai caminhando e se transformando ao longo da história.

Assim, é preciso compreender que a educação escolar, apesar de ter o grande objetivo de desempenhar ações que se pautem no desenvolvimento cognitivo, ela proporciona muito mais do que isso, ela desencadeia experiências de relações sociais, em que vínculos de amizades são formados e também desfeitos, conflitos são vividos, problemas são causados, são solucionados, enfim, são infinitas as emoções que os estudantes passam, ao longo de seus caminhos percorridos nos espaços da educação formal.

A universidade é um desses espaços em que os estudantes passam por experiências de desenvolvimento. Cada estudante passa por essas experiências de uma forma única, percorrendo trajetórias próprias, de acordo com relações estabelecidas no contexto social, econômico e cultural.

O texto está organizado em quatro seções. Na primeira seção apresenta-se a problemática, objetivos bem como as justificativas da pesquisa. Na segunda seção o objetivo é explicitar as escolhas metodológicas. Na seção dedicada as análises são discutidas e as categorias identificadas no processo de investigação. A última seção apresentar as principais conclusões do estudo.

\section{METODOLOGIA}

No processo da pesquisa científica o pesquisador precisa conhecer a natureza de seu trabalho, pois ele faz parte da sua realidade individual. Para Vieira Pinto (1979) é importante 
refletir sobre o trabalho que se executa, os fundamentos existenciais e as finalidades culturais que o explicam, pensando assim, de forma profunda o trabalho científico.

O autor (1979, p. 04) afirma que a ciência pode trazer aos países liberdade política, econômica e cultural, porém ela precisa ser "compreendida por uma teoria filosófica que a explique como atividade do ser humano pensante e revele o pleno significado da atitude de indagação em face da realidade natural e social". Neste sentido, o recorte aqui realizado é parte de uma pesquisa maior que busca compreender processos de internacionalização da Educação Superior brasileira. Nesse sentido, olhar para o processo de desenvolvimento de estudantes pareceu fundamental na construção das análises realizadas.

A pesquisa ora relatada foi realizada com estudantes de graduação do Campus Francisco Beltrão da UTFPR que participaram do CSF. Os dados foram coletados mediante entrevista focada nos motivos que os levaram a participar de uma experiência internacional; nas suas rotinas antes, durante e depois da experiência internacional; nos aprendizados que tiveram no país estrangeiro, que acreditam que não teriam se não tivessem passado pela experiência internacional; e nas mudanças que a experiência internacional trouxe. Para a análise dos dados recorreu-se à Análise de Conteúdo proposta por Bardin (1977).

Esses temas foram abordados com objetivo de entender o processo de desenvolvimento pelo qual eles passaram, quando comparadas as rotinas antes, durante e depois da experiência internacional, bem como suas aprendizagens e mudanças. Essa foi a forma encontrada para entender seus processos de desenvolvimento, já que não se tem como mensurar o quanto o sujeito se desenvolve. É através das mudanças e aprendizagens que ele passa, as quais ele verbaliza, que seu processo de mudança é observado e, consequentemente, seu processo de desenvolvimento é inferido.

Antes de iniciar a coleta de dados, foi realizada uma entrevista piloto para que pudesse ser testado o instrumento de pesquisa. Essa entrevista foi realizada com um estudante participante do CSF, selecionado de forma aleatória, e que teve sua experiência internacional morando nos Estados Unidos. Após o instrumento ser testado e os ajustes terem sido realizados, partiu-se para coleta de dados com os participantes visados.

O primeiro contato com os estudantes foi realizado via e-mail, cuja mensagem continha informações que explicavam quem era a pesquisadora, sobre os objetivos da pesquisa e informações gerais e, por fim, convidavam-nos à participação. O projeto foi aprovado pelo Comitê de Ética em Pesquisa da UTFPR.

\section{AS ANÁLISES REALIZADAS}

No total, 16 estudantes de graduação do Câmpus Francisco Beltrão participaram do CSF. Destes, 13 (81,25\%) participaram do estudo. O grupo era formado por graduandos Engenharia Ambiental, Engenharia de Alimentos, Engenharia Química, Licenciatura em Informática e Tecnologia em Alimentos, 7 estudantes do sexo masculino e 6 do sexo feminino. 
O país que mais recebeu estudantes foram os estados Unidos da América, sendo 5 ao todo, que estiveram nas seguintes instituições: Universidade do Texas e Universidade do Norte do Arizona, 2 estudantes, Universidade do Texas e Universidade do Estado do Arizona, 1 estudante, Universidade do Norte do Arizona, 1 estudante e Universidade da Califórnia, 1 estudante. Para a Alemanha foram 2 estudantes, nas universidades de Trier e Hof. Para o Canadá 2 estudantes, na Faculdade do Rio Vermelho e Universidade de Alberta. País de Gales, Itália, Hungria e Espanha receberam 1 estudantes, na Universidade do Sul do País de Gales, Universidade Ca' Foscari, Universidade de Tecnologia e Economia de Budapeste e Universidade de León, respectivamente. Tempo médio de permanência em cada país foi de 14 meses.

O período de permanência dos alunos no país estrangeiro sugere que o tempo foi suficiente para provocar mudanças importantes em seus processos de desenvolvimento, principalmente no que se refere a organização de rotinas diferenciadas das que estavam acostumados no Brasil, da qual fez parte a linguagem, moradia, horários, rotinas de estudos, opções de lazer, entre muitas outras.

Durante a entrevista alguns estudantes verbalizaram a satisfação em participar da pesquisa, principalmente pelo fato de poderem partilhar as experiência vividas.

O quadro abaixo apresenta os motivos destacados pelos alunos, quando perguntados sobre sobre a participação no Programa:

\begin{tabular}{|c|c|}
\hline MOtıvos & $\begin{array}{c}\text { QUANTIDADE DE ESTUDANTES } \\
\text { RESPONDENTES }\end{array}$ \\
\hline Capacitação/ Oportunidade Profissional & 8 \\
\hline Conhecer/ Aprimorar uma nova Língua & 10 \\
\hline Conhecer outras Culturas/ Países & 3 \\
\hline Crescimento Pessoal & 4 \\
\hline Desejo de Morar Fora do Brasil/ Fazer Intercâmbio & 2 \\
\hline Possibilidade de Viver em um País Desenvolvido & 1 \\
\hline Raízes Familiares na Europa & 4 \\
\hline Questão Financeira & 8 \\
\hline
\end{tabular}

Quadro 2 - Motivos que Levaram os Estudantes a Participarem de uma Experiência Internacional Fonte: Dados de Pesquisa (2016).

Conforme se observa, os principais motivos que levaram os estudantes a participarem de uma experiência internacional foram a vontade de Conhecer outras Culturas e outros Países, Capacitação e Oportunidade Profissional e Conhecer e/ou Aprimorar uma nova Língua. 
O motivo mais frequente de todos foi Conhecer outras Culturas e outros Países, ou seja, dos 13 estudantes, 10 emitiram essa resposta. Os estudantes demonstraram em suas falas que viram no Programa Ciência Sem Fronteiras a oportunidade de satisfazerem seus desejos de morar fora do país e poder conviver com uma diversidade muito grande, seja de pessoas, de hábitos, de alimentação, de rotina, de horários. Enfim, de poder conviver com uma cultura diferente.

O conhecimento e aprimoramento de uma nova língua, a oportunidade de se capacitarem profissionalmente, bem como as oportunidades profissionais que a experiência poderia trazer, foram frequentes também, nas respostas dos estudantes. Essas oportunidades foram vistas por eles como um diferencial em seus currículos, o que poderia trazer uma facilidade para conseguirem emprego futuramente. Pode-se perceber que essa foi uma preocupação mais verbalizada por aqueles que foram para o intercâmbio, na fase mais final de seus cursos de graduação.

Mediante a análise do conteúdo das entrevistas foi possível identificar as categorias Cultura e Autonomia.

\subsection{A categoria Cultura}

O vocábulo cultura evoca múltiplos significados, de modo que seus sentidos estão em disputa no campo ciências sociais. Não obstante a multiplicidade, há acordo quanto ao fato de que cultura é produção humana. Assim, neste trabalho optou-se por considerar a cultura como processo constituinte do sujeito humano, nos moldes da teoria vigotskiana. Com efeito, para Vigotski (1995), a constituição do psiquismo resulta de um processo de apropriação pelo indivíduo dos produtos da cultura humana, porque o desenvolvimento psicológico não é um processo naturalmente orientado.

Todavia, não obstante o fato de o próprio Vigostki não ter aprofundado sua análise sobre os múltiplos significados que esse termo tinha em seu tempo, compreende-se que para o autor cultura tem a ver com a "totalidade das produções humanas (técnicas, artísticas, científicas, tradições, instituições sociais e práticas sociais" (PINO, 2000, p. 54). Por conseguinte, nessa concepção, a cultura tem um caráter técnico e simbólico, quer dizer, está tanto em produtos tangíveis, quanto em ideias. E, nesse sentido, parece adequado estabelecer diálogo com outras tradições teóricas, sobretudo da antropologia interpretativa de Geertz, para melhor explicitar nossa opção por denominar a categoria de análise de que ora se trata, ainda que as diferenças entre Vigotski e Geertz quanto aos pontos de partida e de objeto não possam ser desprezadas.

Se para Vigotski o objeto é o processo de desenvolvimento do psiquismo, para Geertz como antropólogo - o foco volta-se para os processos sociais tecidos pelos homens, os quais, tomando de empréstimo uma expressão de Max Weber, chama de teias de significados. Para Geertz (1989, p. 66), a cultura consiste em um padrão de significados, "um sistema de concepções herdadas expressas em formas simbólicas por meio das quais os homens 
comunicam, perpetuam e desenvolvem seu conhecimento e suas atividades em relação à vida" (GEERTZ, 1989, p. 66).

Portanto, um e outro autor entram no campo da mediação semiótica, e acabam por coincidir quanto a compreensão de que "tornar-se humano é tornar-se individual; a cultura é responsável por criar e produzir singularidades" (FARIA, 2014, p. 76).

Assim, considerando que que cada país possui suas culturas, compostas por uma variedade de costumes, tradições, religiões, línguas, etc. que são elementos que orientam seus habitantes numa forma específica de desenvolverem seus conhecimentos e suas atividades em relação à vida (GEERTZ, 1989), seria de se esperar que os estudantes que participaram desta pesquisa adentrassem em outras teias de significados distintas das suas de origem, de modo que ao final do processo novas singularidades emergissem. Isto é o que tenta demonstrar com a análise da categoria Cultura.

Língua, Visão de Mundo, Preconceito, Hábitos Alimentares, Rotina de Estudos, foram os elementos que emergiram nas entrevistas que embasam o que aqui denominamos pela categoria Cultura.

Um dos elementos principais de uma cultura é a língua. Analisando as entrevistas, todos os estudantes a verbalizaram como uma das principais dificuldades encontradas no início de suas experiências. Um exemplo é a estudante E9, que morou na Espanha, cuja língua é considerada parecida com o português, mas que mesmo assim verbaliza: "A língua, no início é complicado, porque você imagina que o espanhol é uma coisa fácil e você chega lá e é totalmente complicado para entender". Um outro exemplo é o da estudante E5, que foi para a Alemanha, um país com uma língua totalmente diferente do português, em que ela conta: "quando eu fui pra lá, eu não sabia falar nada de alemão e o meu inglês também não era tão bom. Então, a primeira dificuldade foi a língua. Eu falei assim 'meu Deus do céu, eu estou indo para lá e eu não consigo me comunicar com ninguém"'".

A adaptação no país foi dificultada por essa questão, mesmo para aqueles que já tinham um conhecimento prévio da língua de seu país de destino. É o caso do estudante E4, que foi para os Estados Unidos: “No começo, a língua, até o ouvido acostumar, né. Mesmo a gente fazendo aula de inglês foi um pouco... A gente se virava, mas tropeçava um pouco".

Todos os estudantes mencionaram que, ao fim de suas experiências internacionais, tiveram mudanças significativas no que tange a aprendizagem em relação à língua dos países em que moraram. Eles verbalizaram ainda que hoje dominam a língua e têm fluência para se comunicarem facilmente. Um exemplo interessante é o do estudante E4, que morou nos Estados Unidos e quando voltou ao Brasil, conseguiu emprego como professor de inglês: "Por eu ter feito intercâmbio, como eu trabalho como professor de inglês foi algo que eu não tinha como, que eu não ia fazer, apareceu, então, algo diferente. Foi uma oportunidade que apareceu, que eu não teria antes, se eu não tivesse ido".

Neste ponto da análise já se pode verificar tanto o que Knight (2012) alega acerca dos objetivos da internacionalização no sentido da preparação dos estudantes para viver e trabalhar num mundo mais interconectado, para poder interpretar o mundo, para visualizar opções, 
quanto os postulados vigotskianos acerca de que a educação constitui a forma universal do desenvolvimento humano (VIGOTSKI, 1995; LEONTIEV, 1978).

No que tange a alimentação, os estudantes relataram que sentiram várias diferenças, quando comparavam as comidas e refeições brasileiras, com as dos países em que estavam morando. As diferenças dizem respeito ao tempero das comidas, ao tipo de comida, aos horários em que são feitas as refeições, entre outras. Todos eles verbalizaram que sentiram muita falta, principalmente, do feijão, da forma como é preparado no Brasil.

Os estudantes que moraram nos Estados Unidos e na Espanha verbalizaram a diferença do tipo de comida que é servido em cada refeição, pois lá, no café-da-manhã, tem-se o costume de comer alimentos mais gordurosos. E no almoço, o que predomina são os fast foods. Essa foi uma dificuldade que encontraram, já que o costume brasileiro é fazer uma refeição maior, mais completa, na hora do almoço. A fala de um dos alunos é ilustrativa. "...a alimentação lá foi uma questão que ela... eu senti bastante diferença, principalmente no início, até o organismo se acostumar, a você acostumar a tomar um café da manhã onde tenha bacon, onde tenha uma coisa gordurosa, batata frita. É bem difícil, mas você vai pegando o costume e aí você aprende a comer fast food, se sabe que é barato e que rápido. Então a alimentação lá é uma coisa bem diferenciada, uma coisa que eu senti bastante, o meu organismo sofreu um pouco, muita azia, então é uma coisa que demorou para eu acostumar" E3.

Os estudantes que moraram na Alemanha relatam a dificuldade com alimentação, falta do arroz e feijão, porém como são veganos, verbalizam que lá tinham mais opções do que no Brasil, para quem tem essa opção de tipo de alimentação. A estudante E5 conta: "Tem muitas pessoas veganas na Alemanha, na Europa como um todo, assim. Lá tem muita mais opção de restaurante, padaria vegana. Lá é mais fácil. E lá tem muita certificação vegana, é fácil reconhecer os produtos. Aqui você tem que pesquisar muito".

Já a estudante que morou na Itália (E6) deu ênfase ao fato dos tipos de comidas serem servidos separados, diferente daqui do Brasil, em que os ingredientes são misturados no mesmo prato: "Aí ela explicou para gente que o primeiro prato são arroz ou macarrão, são carboidratos. O segundo prato são proteínas. E o terceiro prato são legumes, saladas, coisas que são mais leves assim. E aí eu comecei a entender que, realmente, eles comem separado e não separam só em prato". Outra diferença ressaltada por ela foi a questão de serem vendidas bebidas alcóolicas dentro da universidade: "E aí no RU, a gente viu que, mesmo sendo um restaurante universitário, tinha a opção de vinho ou a cerveja, porque eles têm costume de comer com vinho ou cerveja. Para eles é uma coisa totalmente familiar, totalmente normal. Não é... Eu vou me embebedar, eu vou beber, porque eu quero beber. Não, é porque estou almoçando, então eu vou beber um vinho".

Os depoimentos dos estudantes entrevistados demonstram diferenças culturais em relação a alimentação e as adaptações pelas quais os estudantes tiveram que passar, para poderem se adequarem aos costumes dos países em que passaram suas experiências internacionais. Pode-se perceber que cada um teve uma experiência diferente, uns tendo maior facilidade e outros nem tanto. Teresa Rego (2003) aponta que essa experiência diferenciada de cada estudante relaciona-se ao que segue: 
a singularidade de cada indivíduo não resulta de fatores isolados (por exemplo, exclusivamente da educação familiar recebida, do contexto sociopolítico da época em que viveu, da classe social a que pertence, etc.), mas da multiplicidade de influências que recaem sobre o sujeito no curso de seu desenvolvimento (REGO, 2003, p. 54-55).

Outro aspecto pesquisado foi em relação às atividades de lazer que os estudantes participaram em suas experiências. Cada estudante relatou as atividades que realizavam, principalmente, nos finais de semana. Essas atividades eram muito variadas, dependendo do país, cidade e estudante que estava relatando. Aqueles que conviviam com mais brasileiros contam que uma atividade que era sempre feita era reunir os amigos, na janta ou no almoço, para fazerem comidas brasileiras. Em muitos desses encontros também participavam, além dos amigos brasileiros, convidados do país estrangeiro em que estavam morando, bem como pessoas de outros países que também eram intercambiários. Era um dos momentos em que eles aproveitavam para se distraírem e, ao mesmo tempo, mostrarem seus costumes e culturas e aprenderem mais sobre os costumes e culturas de seus novos amigos. Os estudantes E5 e E7, respectivamente, contam suas experiências: "eu saía muito com os alemães, então, os amigos, a gente sempre fazia noite de jogos. Era bem divertido, para praticar a língua, para aprender mais sobre, emergir, realmente, na cultura"; "Ah, a gente se reunia com os amigos e ia pra balada. A gente cozinhava junto também. A gente confraternizava bebendo cerveja".

Muitos deles contam que iam aos parques de suas cidades, lagos, museus, monumentos, shopping, bares, festas, entre outros. Segue um exemplo dessa experiência do estudante E11 que morou no Canadá: "Como é uma cidade grande, você tem bastantes opções para sair, tinha bastantes bares. Tinha bastantes parques também. Cinema. Shopping lá é bem grande também".

Além das atividades de lazer que eram realizadas nas próprias cidades em que os estudantes moravam, eles também realizaram várias viagens, principalmente nos feriados e período de férias, além dos fins de semana, quando os lugares a serem conhecidos eram próximos. E8: “Então, eu entrava na van com eles e a gente ia acampar, passava o final de semana numa outra província, porque era tudo, relativamente, perto. Então, a gente buscava um lago, sempre no final de semana um lago diferente e acampava, quando eu tinha disponibilidade".

Um dado interessante é que todos os estudantes pesquisados, quando questionados no que tange ao lazer, deram maior ênfase para as viagens que puderam realizar no período em que estavam morando fora do Brasil. Alguns deles contam que só puderam realizar essas viagens por estarem participando do Ciência Sem Fronteiras e recebendo bolsas, que custeavam suas despesas rotineiras, as quais tentavam economizar, para que pudessem conhecer outros lugares.

A maioria dos estudantes que moraram nos Estados Unidos e no Canadá conheceram os países em que estavam residindo, principalmente pelas oportunidades e extensão destes. 0 estudante E4 conta: “A gente morava perto de Los Angeles, então lá a gente tem muita coisa para fazer". Outro exemplo é o do estudante E8: "Nas férias de julho de 2014 a gente acabou alugando uma van, uns colegas da Coreia e da China, que eu fiz lá e alguns brasileiros, a gente alugou uma van e acabou indo para uma outra província mais distante, para conhecer, também, uma outra parte do Canadá. E antes de eu retornar, eu fui um pouco mais para o Norte do 
Canadá, para passar um pouco mais de frio, para ver a Aurora Boreal e fazer snowboarding, esse tipo de esporte".

Já os que moraram na Europa relataram terem feito, além das viagens próximas as suas cidades, viagens internacionais, justificando que há uma grande facilidade de locomoção de um país para o outro, seja de trem ou de avião. Verbalizaram que os países são próximos um do outro e os valores das passagens são acessíveis. E5: "Você pode viajar para qualquer lugar, assim, porque tem os trens e tal, tem muito tipo diferente de transporte. Você pode viajar toda a Europa de trem e é barato também, o custo não é tão elevado. Aproveitei para viajar para outros lugares também, nas férias. Depois daquele semestre todo pesado e como eu tinha três meses de férias, então, eu fui pra vários países: Luxemburgo, Espanha, Polônia, República Tcheca, Viena na Áustria. Deu para aproveitar bastante também esse lado".

Essas experiências de lazer de passeios em suas próprias cidades de moradia, em lugares próximos ou de viagens a outros países foram muito significativas para eles, pois foram momentos que puderam vivenciar as tradições, a história dos países e, até mesmo, a história em que estudamos nos livros aqui no Brasil ou de fatos e lugares divulgados pela mídia, mas que poucos têm a oportunidade de ver de perto, de tocar e de se relacionar com pessoas que fazem parte daquela história. Pode-se perceber que essas experiências implicaram em novos aprendizados, novas formas de interpretações do mundo e da vida.

Outro aspecto importante pesquisado com os estudantes foi a questão das aprendizagens e mudanças que eles tiveram, em relação à rotina de estudos. Todos eles verbalizaram que suas rotinas de estudo, quando estavam passando pela experiência internacional, modificaram-se de forma significativa. Eles atribuem essa modificação, pelo fato do sistema de ensino dos países estrangeiros onde moraram, ser diferente do sistema do Brasil. Afirmam que as cargas horárias dentro das salas de aula não eram tão grandes, quanto as daqui do Brasil. Dessa forma, tinham menor exigência de estarem presentes em sala de aula, porém uma grande carga de trabalho e estudos para serem desempenhados fora da sala de aula, seja em casa, na biblioteca, em laboratórios, entre outros.

Uma das estudantes que morou nos Estados Unidos, E12, conta: "Lá eu fazia só quatro matérias, era o máximo que podia fazer, quatro ou cinco matérias. Eu fazia quatro. Então as aulas eram... Tinha poucas aulas. Cada matéria eram no máximo três horas semanais ou quatro, quando tinha laboratório. Então, tinha bastante tempo livre, porque lá o sistema é bem diferente assim, eles... A gente tem muita coisa para fazer em casa, muita coisa para estudar, muito trabalho, muita leitura e menos horas de sala de aula". Um dos alunos que morou no Canadá, E8, fala sobre sua adaptação: "eu tive que estudar bem mais, aprender uma nova maneira de estudar, adaptar o sistema de provas e avaliação deles. Então, eu me tornei um aluno bem melhor". É possível perceber na fala desse aluno um desenvolvimento significativo, observado através de sua autoanálise. A experiência do sistema de ensino no País de Gales, que a estudante E1 vivenciou, é relatada por ela, que diz "Eles davam os trabalhos para gente, como se a gente já tivesse ali formado e tivesse que fazer um super projeto. Então, você tinha que ir atrás e fazer na prática mesmo. Eu acho que esse foi um grande aprendizado na área, que eu não teria aqui, com certeza". 
Rego (2003, p. 410-411) ressalta que

\begin{abstract}
as variadas práticas escolares podem produzir diferentes efeitos nos alunos (capazes, por exemplo, de influenciar determinados comportamentos e sentimentos em relação ao saber). Mas esses efeitos nunca serão exatamente os mesmos para todos os estudantes, ainda que submetidos a um mesmo modelo educativo. A escola é vivida por todos, mas tem, para cada um, sentidos diferentes. Isso se deve ao fato de que o impacto da escolarização nas diferentes trajetórias individuais ultrapassa a questão do método pedagógico vigente nas instituições escolares. $O$ tipo de influência e as marcas da escola dependerão de vários fatores, entre eles, a origem social dos alunos, a importância outorgada à escola, o tipo de expectativa depositada no aluno, o reconhecimento de seu esforço e empenho pela escola, etc.
\end{abstract}

Essa rotina diferenciada pela qual os estudantes passaram no país estrangeiro trouxe modificações para suas rotinas aqui no Brasil, depois que voltaram para suas universidades de origem. Eles contam que passaram a ter mais foco nos seus cursos de graduação, passaram a estipularem objetivos e metas e estavam se esforçando até mais do que antes da experiência, para cumpri-las. Aprenderam também a não desistir, quando algo está se demonstrando difícil, pois viram que muitas pessoas as quais conviveram, lutam de todas as formas e quantas vezes for preciso, até atingirem o que querem. A seguir, dois exemplos: E10: "Eu acho que eles colocam na cabeça deles e eles seguem aquilo e é aquilo que eles vão conseguir. Eles têm uma forma, uma disciplina de se fazer as coisas, que eu ficava muito admirada de ver. $E$ eu acho que isso também me ajudou a me tornar uma pessoa disciplinada". E8: "Eu procuro, desde que eu voltei, eu procuro aproveitar muito mais o meu dia. Antes, não que eu não aproveitasse, mas a minha rotina no Canadá era tão corrida, que eu via que em meio dia, as atividades que eu fazia lá, era equivalente a um dia meu aqui, praticamente. Então, eu aprendi a dormir menos, pra aproveitar mais, não só para produzir mais, mas para aproveitar mais o dia. Então, é uma questão que eu melhorei também".

Um outro dado interessante foi que vários alunos disseram que se tornaram menos preconceituosos ou deixaram de ser preconceituosos. Eles relatam que isso foi possível por conviverem com muitas pessoas diferentes, com costumes diversos dos deles, religiões diferentes, visões de mundo diferentes, entre outras. Afirmaram que além de conviverem com pessoas dos países em que estavam morando, relacionaram-se também, com pessoas de outros países, como por exemplo, árabes, chineses, iraquianos, japoneses, que também eram intercambiários. Muitos verbalizam que as informações que tinham sobre essas culturas, sobre esses países, muitas vezes vinham da mídia e que hoje, após terem passado pela experiência internacional, julgam de forma totalmente diferente. Essas mudanças podem ser observadas nas falas a seguir: E6: "Porque lá eu conheci muitas feministas. Eu não sou feminista e nunca fui e lá eu entendi o que era o feminismo, entendi o que era, o que o grupo queria, como que é, como que funcionava. E também tive contato com... Lá eles têm um grupo muito organizado antifascista e daí eu comecei a entender como, o que era o antifascismo lá deles. E pra mim foi o maior ganho, assim, abrir a mentalidade mesmo, para várias outras mentalidades que existem, não só a nossa". E4: "Aí depois eu morei em um apartamento maior, que eram 6, dois por quarto. Daí tinha um sueco, iraniano, americano. Aí eu... Que eram gente boas também, aí deu para 
conhecer muito da cultura deles também, perder um pouco também dessa... Do preconceito que a gente vê pela TV, sabe?!"

A categoria Cultura ajudou a compreender, nesta pesquisa, mudanças sobre a visão de mundo dos estudantes. Eles relatam que passaram a enxergar o mundo, a vida de uma forma diferente e isso trouxe mudanças para suas formas de se comportarem, de agirem, de pensarem. Essa mudança pode ser observada nas falas a seguir: E1: "Eu acho que é isso que trouxe, minha visão de mundo... De fronteiras... De mim mesma. E eu conheci muita gente que eu quero levar para o resto da vida, continuo conversando até hoje". E4: "Então, eu tenho uma visão diferente do que eu tinha antes, porque eu penso... Antes de ter ido, eu era um E4 até tal limite. Depois que eu fui pra lá, eu ganhei muita coisa, não só inglês, mas também experiência, a visão que eu ganhei lá também. Então, eu vejo que eu estou melhor do que eu era antes. Então, eu busco o meu limite. O meu horizonte é maior hoje". E5: "Também, é, no sentido que você cresce muito enquanto pessoa, não sei, você volta com a cabeça diferente. Quando você vê outra cultura, você começa a olhar as coisas com olhar diferente, um outro ângulo, uma visão diferenciada".

A forma como cada sujeito se relaciona com a escola depende de vários aspectos, entre eles, as esperanças para o futuro que a escola representa, a autoestima do sujeito, as expectativas nele depositadas e os estímulos recebidos ao longo de sua formação. É necessário que se reconheça que os efeitos da escolarização dependem, além de outros fatores, do professor, do tipo de prática pedagógica realizada e das experiências que a escola proporciona. Dessa forma, "não é qualquer ensino que promove o desenvolvimento" (REGO, 2002, 69).

Assim,

\begin{abstract}
a aprendizagem não mobiliza apenas a dimensão cognitiva mas também afetos, emoções e relações interpessoais. E que, embora as ações da escola se dirijam, na maior parte das vezes, ao desenvolvimento do aspecto cognitivo, as dimensões cognitivas, emocionais e sociais não se separam na prática escolar. Pelo contrário, para o aluno esses diferentes âmbitos se interpenetram e se contaminam, já que estão intimamente relacionados. A dinâmica presente nessa relação reforça também a importância de se buscar, no campo da psicologia e da educação, a integração entre essas diferentes dimensões, tendência bastante presente nas discussões contemporâneas (REGO, 2002, p. 71).
\end{abstract}

O ser humano se desenvolve na medida em que ele vai sendo educado por intermédio de outros, através da linguagem e do sentido que ele vai dando para o mundo ao seu redor, bem como do estabelecimento de relações com esse mundo. Dessa forma, uma das maneiras de desenvolvimento é a educação escolar, que exerce um papel fundamental na formação cognitiva do sujeito, mas também, nas suas experiências de sociabilidade, de interações com as pessoas e com os conhecimentos e nas experiências pessoais, de forma geral. A educação escolar/universitária, com ações intencionais e planejadas, como a Internacionalização, pode trazer uma maior amplitude no desenvolvimento humano de estudantes que estão buscando a formação profissional, em um mundo que nos cobra que pensemos globalmente.

A esse respeito Rego (2003, p. 30) menciona a importância que Vigotski dá para a educação e o aprendizado escolar: 
Ele acredita que o aprendizado escolar introduz elementos novos no desenvolvimento da criança, apesar de reconhecer que o aprendizado se inicie muito antes do ingresso na escola. Vigotski sublinha que a escola, por oferecer conteúdos e desenvolver modalidades de pensamento bastante específicos, tem um papel diferente e insubstituível na apropriação, pelo sujeito, da experiência culturalmente acumulada.

Rego (2003) afirma que os traços que irão caracterizar a criança e o jovem não dependem exclusivamente do que eles vivenciarem no interior da família, "mas das inúmeras aprendizagens que o indivíduo realizará em diferentes contextos socializadores, entre eles, a escola" (REGO, 2003, p. 57), entendida pela autora como um local em que deve se "oferecer a oportunidade de ele ter acesso a informações novas e desafiadoras [...], capazes de provocar transformações e de desencadear processos de desenvolvimento e comportamento (REGO, 2003, p. 58). Dessa forma, é necessário que se reconheça o "potencial transformador das experiências escolares" (REGO, 2003, p. 58).

Partindo dessa ideia, pode-se perceber nos estudantes o quanto eles verbalizaram as transformações que eles tiveram e a evidência que se teve em suas falas, em relação a mudanças na aquisição de autonomia.

\subsection{A categoria Autonomia}

Considerando que o desenvolvimento humano é um processo mediado pela cultura, então pode-se dizer a produção de singularidades é um processo educado. Com efeito, na visão Leontiev (1978), quando o indivíduo, ao adquirir as condições básicas para sobreviver, adquire, também, uma visão de mundo, um conjunto de significados aos quais dá sentido de acordo com seus motivos (teia de significados no dizer de Geertz), tendo em vista que as relações entre os humanos são sempre mediadas pela linguagem. Observa-se no autor citado que a constituição do sujeito é um processo de duas vias, visto que se é o próprio sujeito que atribui sentidos ao conjunto de significados nos quais está imerso, então é porque não há passividade.

O desenvolvimento humano é movimento, é mudança. Então, se em função das interações interpessoais mediadas semioticamente o sujeito vai se apropriando de maneira ativa das significações de seu meio histórico-cultural e lhe dá um sentido próprio (VIGOTSKI, 1995), pode-se dizer que esse processo vai gerando autonomia. E nesse processo, como se disse antes a partir de Rego (2003), o indivíduo se desenvolve a partir de inúmeras aprendizagens que realiza em diferentes contextos.

Nesta pesquisa, os estudantes relatam importantes mudanças em suas atitudes frente a vários aspectos de suas vidas. as entrevistas com os estudantes surgiram os elementos Independência, Maturidade, Responsabilidade, Autoconhecimento, Coragem e Disciplina, os quais, por sua vez, sustentam o que denominamos como a categoria Autonomia neste estudo.

Observou-se que a rotina de estudos, para a grande maioria dos estudantes pesquisados, após terem voltado para o Brasil, para a UTFPR Câmpus Beltrão, modificou. Os estudantes 
demonstram terem aprendido uma nova forma de estudar, um novo jeito de se organizarem e de se planejarem, a partir da experiência internacional que tiveram. Relatam que se tornaram mais autônomos e menos dependentes de estímulos externos para realizarem suas tarefas rotineiras na universidade. É o caso do estudante E13: “Ah, dessa parte de ser mais independente, de estudar mais independentemente, não esperar que o professor vai me falar alguma coisa que eu estou em dúvida. Se eu estiver com aquela dúvida, eu mesmo vou ler, eu mesmo vou questionar o professor, eu mesmo vou me interessar por aquilo". Outro relato interessante é o da estudante E1, que morou no País de Gales: "Uma coisa que, assim, eu não tinha antes essa coisa de tomar a iniciativa. Eu sempre ficava muito, sabe, parada. Tanto que, nossa, os primeiros anos da minha faculdade eu olho e gente, eu não fiz nada, sabe, que desperdício, eu podia ter feito tanta coisa. Então, eu acho que agora eu tenho mais coragem, assim, de tomar a iniciativa, que eu não tinha antes".

Analisando as entrevistas dos alunos que moravam com seus pais, antes de participarem da experiência internacional e passaram a morar sozinhos pela primeira vez, é possível perceber que tal experiência causou várias modificações neles. É o caso da estudante E11, que foi morar no Canadá e nunca tinha saído de casa: "Eu acho que para mim, como eu moro com os meus pais aqui, eu acho que foi a mesma experiência de alguém que vai morar em outra cidade, para estudar. Eu acho que seria isso, você aprender a se virar sozinha, né, e fazer as coisas por você. Tudo é você que tem que correr atrás. Eu acho que isso te dá um crescimento pessoal. É legal". Uma outra experiência é a da estudante E10: "Como pessoa eu acho... É... Foi acho que o que eu mais ganhei, digamos. Não só, mas eu acho que eu era muito introvertida, muito... Quase não falava, tinha medo de falar com as pessoas, me virava muito pouco sozinha, porque também morei a vida inteira com os meus pais, então, e o meu pai, de certa forma, ele às vezes reclamava 'mas você tem que se virar!', mas acabava indo lá e fazendo. Então, sempre fui muito dependente". Outro exemplo é o do aluno E8: "Então, eu voltei muito mais desapegado dessa questão, de ficar no Brasil, necessitar estar perto da família. Nessa questão com certeza eu mudei".

Em relação a esses alunos observa-se que o fato de morarem com seus pais e passarem pela experiência internacional, morando sozinhos em outro país, trouxe a eles aprendizados e mudanças muito significativas. Com essa experiência, precisaram dividir o espaço de suas casas e, até mesmo, o próprio quarto, bem como resolverem e superarem conflitos estabelecidos na convivência diária, com pessoas as quais não tinham intimidade.

É preciso ressaltar que os estudantes que já moravam sozinhos, longe de suas famílias, antes da experiência internacional, também sofreram implicâncias em seus desenvolvimentos, em relação as mudanças e aprendizados acima citados, porém elas não foram verbalizadas por eles com tanta ênfase, quando comparadas com os alunos que saíram de casa pela primeira vez. Entende-se que, possivelmente, não deram ênfase, pelo fato de já terem aprendido e superado os vários conflitos e desafios das adaptações necessárias proporcionadas pela saída da casa da família. A esse respeito, seguem as falas de dois estudantes: E2: "eu não tive tanto essa dificuldade de me adaptar ficar sem os pais, porque eu morava aqui já sem meus pais, né, então eu já estava aqui desde 2010 e estava sem meus pais"; e E6: "E no dia a dia mesmo não mudou 
muito, porque como eu já morava fora com estudantes, eu continuei morando com estudantes e quando eu voltei, continuei morando com estudantes".

Porém, eles verbalizaram que passaram a valorizar mais ainda suas famílias, demonstrando um desejo de ficarem mais próximos deles, assim que voltassem ao Brasil e terminassem seus cursos. A estudante E6 menciona "Eu ficava pensando, não, agora eu vou terminar a faculdade e vou voltar para uma cidade mais perto, porque eu quero ficar mais perto dos meus pais e da minha família". Outro exemplo é o da estudante E9: "A relação familiar, eu fiquei bem mais apegada. Nossa, quando eu fui para fora, isso me... Porque assim, eu e minha mãe não éramos tão ligadas de se falar todo dia, mas quando eu estava fora não, a gente se falava o tempo todo".

Os estudantes foram questionados sobre as aprendizagens que acreditam que tiveram no país de destino e não teriam se não tivessem passado pela experiência internacional. As respostas foram inúmeras e foi perceptível as implicações que a experiência internacional trouxe para o desenvolvimento humano. Além das já mencionadas, foi possível observar que eles passaram por muitos novos desafios, que geraram aprendizados e mudanças, que dizem respeito a maior independência, mais responsabilidade, mais coragem, mais autoconhecimento, maior autoconfiança, desejo de mais liberdade, entre outras, que são elementos que sustentam o conceito de autonomia, como uma das categorias de análise. A seguir, algumas falas que ilustram essa discussão:

E1: "Só de morar em um ambiente tão diferente, eu acho que a gente já aprende muito sobre nós mesmos". E1: "Mas, outro exemplo também de independência, eu não tinha coragem de dirigir antes de ir pra lá. Então, meus pais tinham que me levar de um lado para o outro e eu voltei decidida a pegar o carro, desde que eu cheguei do intercâmbio eu tô dirigindo".

E3: "Então, a gente consegue ter uma maturidade de como conversar, da maneira de se expressar. Então, acho que essa foi a parte mais bacana, fora a parte também de conhecimento, que você volta mais responsável, você volta com foco, você vê coisas maravilhosas lá e você quer voltar e aplicar isso. Então, essas foram as grandes mudanças que eu acho que foi sabe".

E4: "É essa coragem que eu ganhei. Antes eu não era, como eu posso dizer, "carudo" assim, de enfrentar as coisas e as pessoas. Então, com essa experiência lá eu ganhei isso. Hoje eu corro muito mais atrás das coisas, do que eu corria antes. Acho que me mudou bastante".

E6: "E é uma coisa que você tem que passar por situações para provar para você mesma que você é capaz e foi isso que eu consegui lá. Talvez eu iria continuar achando que eu não era capaz. Ou aprenderia na marra também aqui no Brasil, mas foi bem mais fácil depois que eu fui para lá e vi que eu era capaz de fazer coisas que talvez eu não achasse que tinha capacidade".

E9: "Me amadureceu mais, eu acho que é essa a palavra. Eu fiquei mais responsável em relação ao que eu quero para mim. Antes eu era mais responsável 'tô aqui gastando o dinheiro da minha mãe', mas só. Agora não, eu quero concretizar o que planejei, minhas metas, eu quero acabar. Acho que isso me ajudou bastante".

E10: “Outra mudança foi de eu ter que me virar sozinha, de eu ter minha autonomia que eu criei lá fora, porque aqui eu, realmente, não tinha autonomia, praticamente nenhuma". 
E12: "Acho que a gente volta com uma visão completamente diferente das coisas. A gente começa a valorizar coisas que a gente antes não valorizava, tempo em família. Isso é uma coisa que eu aprendi com outras culturas que eu vi".

Um dos conceitos centrais desta pesquisa é o conceito de desenvolvimento humano, entendido como processo de mudança e esse processo ocorre a partir das várias aprendizagens que o sujeito vai tendo, com base nas relações sociais que ele vai estabelecendo.Cada estudante deu à sua experiência um significado diferente, mas todos eles demonstraram terem tido oportunidade de terem novos aprendizados e de terem passado por mudanças importantes em suas vidas. Dessa forma, a partir de um longo processo de análise, pode-se inferir que a experiência internacional, proporcionada pelo Programa Ciência Sem Fronteiras, trouxe a cada um dos estudantes um processo de mudança, ou seja, ela proporcionou a eles implicações em seus desenvolvimentos humanos; imersões em novas teias de significados.

\section{CONSIDERAÇÕES FINAIS}

Neste artigo relatamos uma investigação que teve por objetivo analisar como experiências de internacionalização desenvolvidas no âmbito do Programa Ciência sem Fronteiras implicam o desenvolvimento humano de estudantes de graduação.

Por conseguinte, um dos conceitos centrais desta pesquisa foi o de desenvolvimento humano, entendido como processo de mudança que ocorre a partir das várias aprendizagens que o sujeito vai tendo, com base nas relações sociais que ele vai estabelecendo. Quando o estudante relata como ele era antes da experiência internacional e como ele se tornou depois, podemos inferir que ele se modificou, que ele passou por novos aprendizados e, por consequência, ele se desenvolveu.

Cada estudante deu à sua experiência um significado diferente, mas todos eles demonstraram terem tido oportunidade de terem novos aprendizados e de terem passado por mudanças importantes em suas vidas. Dessa forma, a partir de um longo processo de análise, pode-se inferir que a experiência internacional, proporcionada pelo Programa Ciência Sem Fronteiras, trouxe a cada um dos estudantes um processo de mudança, ou seja, ela proporcionou a eles implicações em seus desenvolvimentos humanos.

A pesquisa evidenciou o processo de escolarização agindo no sentido do desenvolvimento humano, no sentido que este é concebido na perspectiva vigotskiana. É através da escola que o sujeito entra em contato com conhecimentos científicos e se desenvolve cognitivamente, porém os estudantes vivenciam muito além disso nos seus anos escolares. Suas experiências passam pela interação com pessoas diversas, por situações pessoais diferentes, por conflitos, em que são necessárias resoluções, enfim, passam por inúmeras relações sociais que produzem emoções, aprendizados e mudanças que vão muito além do desenvolvimento cognitivo e que são de extrema importância para que o desenvolvimento humano aconteça. 
Muito além dos conhecimentos científicos que os estudantes puderam ter, por estarem dentro de uma universidade em um país estrangeiro, foram as experiências vivenciadas na inserção de uma cultura diferente que lhes trouxeram as maiores implicações para suas vidas. É preciso ressaltar que todas essas experiências vivenciadas, trouxeram modificações de uma forma integral, seja de ordem pessoal, social, etc e essas mudanças também são partes integrantes da formação profissional. É preciso considerar que se os estudantes se tornaram mais autônomos, menos preconceituosos, mais disciplinados, mais responsáveis, mais tolerantes, mais respeitos no que tange a diversidade, se ampliaram suas visões de mundo, consequentemente, eles serão melhores em sua trajetória acadêmica e serão melhores profissionais, pois as questões de ordem pessoal e profissional estão conectadas o tempo todo.

Na pesquisa ficou evidente que a experiência de morar e estudar fora do Brasil, trouxe a cada um deles aprendizados e mudanças diferentes, de acordo suas trajetórias percorridas. Porém, dois aspectos foram significativos para eles, que foi a questão da Cultura e da Autonomia, que são as categorias que emergiram a partir das entrevistas analisadas.

Compreendeu-se que cada estudante, mesmo morando nos mesmos países, expressou suas impressões sobre a cultura do país estrangeiro, de maneiras diferentes. Além da convivência com a cultura do seu país de moradia, eles também puderam conviver com outros estudantes, também intercambiários, de outros países e, consequentemente, de outras culturas. Eles verbalizaram sobre as diversas culturas, falando sobre os diferentes costumes, tradições, políticas, economias, religiões e línguas, que são elementos que estão na base do viver, de se relacionar entre as pessoas e que constroem diversidade de interpretações do mundo.

Os estudantes mencionaram que a convivência com novas culturas trouxe a eles muitas aprendizagens e muitas mudanças, sendo as mais significativas em relação ao domínio de uma nova língua, mudança de visão de mundo, de abandono de preconceitos, de mudança de hábitos alimentares e de aprendizagem de uma nova rotina de estudos. Essas aprendizagens permaneceram após o retorno deles ao Brasil, o que mostra que o processo de mudança ocorreu, modificando o cotidiano.

No que se refere à categoria Autonomia, os estudantes verbalizaram sobre suas mudanças no que diz respeito a maior independência, maturidade, responsabilidade, autoconhecimento, coragem, disciplina e foco, que são elementos que ajudam a compreender o quão autônomos os alunos se tornaram.

As implicações maiores, no que tange a autonomia, parecem ter ocorrido para aqueles que nunca haviam morado fora da casa de suas famílias, pois esses tiverem muitas aprendizagens, que os estudantes que já haviam saído de casa para estudar, haviam passado anteriormente. Porém, todos eles mencionaram que passaram por situações diferentes das que já haviam passado no Brasil e afirmaram que não passariam por elas, se não tivessem passado pela experiência internacional. Vivenciaram uma nova rotina, com novos desafios, novos aprendizados e muitas mudanças.

Grande parte das aprendizagens e mudanças que foram adquiridas a partir da experiência internacional, vivenciadas no país estrangeiro, permaneceram após o retorno ao Brasil, algumas mudanças com maior intensidade e outras com menor. Dessa forma, pode-se inferir que o 
desenvolvimento ocorreu, pois houve processo de mudança, devido aos próprios estudantes verbalizarem suas modificações e apontarem de que forma eles eram antes da experiência internacional e depois dela.

\section{REFERÊNCIAS}

Bardin, L. (1977) Análise de Conteúdo. Lisboa: Edições 70, 280p.

BIDO, M. C. F. (2016) Ciência Com Fronteiras: a mobilidade acadêmica e seus impactos. Curitiba: CRV, 142p.

Cunha, M. I. \& Reschke, M. J. D. (2016) Internacionalização da Educação e Mobilidade Estudantil em Questão. In: Reunião Científica Regional da Anped. Curitiba: ANPED, 2016. Recuperado de http://www.anpedsul2016.ufpr.br/wp-content/uploads/2015/11/eixo8_MARIA-ISABELDA-CUNHA-MARIA-JANINE-DALPIAZ-RESCHKE.pdf

Faria, T.B.B.C. (2014) Aproximações entre a antropologia interpretativa de Clifford Geertz e a perspectiva histórico-cultural de Lev Vigotski. (Dissertação de Mestrado). Faculdade de Educação - UNICAMP, Campinas, SP, Brasil, 90p.

Gerrtz, C. (1989) A interpretação das culturas. Rio de Janeiro: LTC, 224p.

Knight, J. (2010) Internacionalização da educação superior novos desenvolvimentos e consequências não intencionadas. Boletim IESALC Informa de Ensino Superior. Recuperado de http://150.185.8.110/previo/index.php?option=com_content\&view=article\&id=2418\%3Aint ernacionalizacion-de-la-educacion-superior-nuevos-desarrollos-y-consecuencias-nointencionadas \&catid=126\%3Anoticias-pagina-nueva\&ltemid=712\&lang=br

Knight, J. (2012) Cinco verdades sobre internacionalização. International Higher Education. Publicação trimestral do Center for International Higher Education. Journal for Studies in International $\quad$ Education. $\quad$ N. $69 . \quad$ Recuperado de http://www.revistaensinosuperior.gr.unicamp.br/edicoes/ihe/IHE69port.pdf

Knight, J. (2014) Universidades apostam na internacionalização. Entrevista concedida para Grazieli Gotardo. Jornal Extra Classe, Julho, 2014. Recuperado de: http://www.extraclasse.org.br/edicoes/2014/07/universidades-apostam-nainternacionalizacao

Leontiev, A. N. (1978) O desenvolvimento do psiquismo. Lisboa: Livros Horizonte, 356p.

MEC (2015). Ciência Sem Fronteiras. Ministério da Educação: Brasília, Brasil. Recuperado de http://www.cienciasemfronteiras.gov.br/web/csf/o-programa

Morosini, M. C. (1997) Internacionalização de Sistemas Universitários: o Mercosul. In: Sguissardi, V. \& SILVA JUNIOR, J. R. (Org.). Políticas Públicas para a Educação Superior. Piracicaba: UNIMEP, pp 225-254.

Morosini, M. C. (2006) Internacionalização da Educação Superior: um modelo em construção? In: Audy, J. L. N. \& Morosini, M. C. (Org.). Inovação e Empreendedorismo na Universidade. Porto Alegre: EDIPUCRS, pp. 189-210. 
Oliveira, M. K. \& Teixeira, E. S. (2002) A questão da periodização do desenvolvimento psicológico. In: Oliveira, M. K; Rego, T. C.; \& Souza, D. T. R. (Org.). Psicologia, Educação e as Temáticas da Vida Contemporânea. São Paulo: Moderna, pp. 23-46.

Pino, A. (2000) O social e o cultural na obra de Vigotski. Educação e Sociedade. Ano XXI, n. 71, pp. 45-78.

Pino, A. (2005) As marcas do humano: as origens da constituição cultural da criança na perspectiva de Lev S. Vigotski. São Paulo: Cortez, 303p.

Rego, T. C. (2002) Configurações sociais e singularidades: o impacto da escola na constituição dos sujeitos. In: Oliveira, M. K; Rego, T. C.; \& Souza, D. T. R. (orgs.). Psicologia, Educação e as Temáticas da Vida Contemporânea. São Paulo: Moderna, pp. 47-76.

Rego, T.C (2003). Memórias de escola: cultura escolar e constituição de singularidades. Petrópolis: Vozes, 420p.

Teixeira, E.S. (200) Vigotski e o materialismo dialético: uma introdução aos fundamentos filosóficos da psicologia histórico-cultural. Pato Branco: Fadep, 138p.

Vigotski, L. S. (1995) Génesis de las funciones psíquicas superiores. In: Vigotski, L. S. Obras Escogidas. Tomo III. Madrid: Visor/ MEC, pp. 139-168.

Vigotski, L. S. (2012) Aprendizagem e Desenvolvimento Intelectual na Idade Escolar. In: Vigotski, L. S.; Luria, A. R. \& Leontiev, A. N. Linguagem, Desenvolvimento e Aprendizagem. São Paulo: Ícone Editora, pp 21-58.

Vieira Pinto, A. (1979) Ciência e Existência. Rio de Janeiro: Paz e Terra, 537p. 